\title{
Prevention of deep vein thrombosis after hip replacement: randomised comparison between unfractionated heparin and low molecular weight heparin
}

\author{
P F Leyvraz, F Bachmann, J Hoek, H R Büller, M Postel, M Samama, M D Vandenbroek
}

Vaudois University

Hospital, 1011 Lausanne, Switzerland

PF Leyvraz, MD, orthopaedic surgeon

$\mathrm{F}$ Bachmann, MD, professor in haematology

Centre for Haemostasis, Thrombosis,

Arteriosclerosis

and Inflammation

Research, Academic

Medical Center, 1105 AZ

Amsterdam, The

Netherlands

J Hoek, MD, research fellow

H R Büller, MD, medical

registrar

\section{Hôpital Cochin, 75674}

Paris

M Postel, MD, professor in

orthopaedic surgery

Central Laboratory, Hôtel-Dieu, 75181 Paris

M Samama, MD, professor in

haematology

Sanofi Research, 94256

Gentilly, France

$M$ D Vandenbroek, MD,

international project

manager

Correspondence to:

Dr Leyvraz.

BMJ 1991;303:543-8

\section{Abstract}

Objective-To evaluate the efficacy and safety of two subcutaneous prophylactic regimens for postoperative deep vein thrombosis after total hip replacement.

Design-Prospective open randomised multicentre trial.

Setting-28 European departments of orthopaedic surgery.

Intervention-All patients had bilateral phlebography 10 days after surgery. 31 patients receiving low molecular weight heparin and 29 receiving unfractionated heparin were excluded from the efficacy analysis for various reasons.

Patients -349 patients undergoing total hip replacement between September 1988 and May 1989. 174 patients received subcutaneously a low molecular weight heparin (Fraxiparine) with anti-factor $\mathrm{Xa}$ activity of $41 \mathrm{IU} / \mathrm{kg} /$ day for three days, then $62 \mathrm{IU} / \mathrm{kg} / \mathrm{day}$ from day 4 to day 10.175 patients received subcutaneous unfractionated heparin at intervals of eight hours; doses were adjusted to maintain the activated thromboplastin time at two to five seconds above control values.

Main outcome measure-Total incidence of deep vein thrombosis and incidence of proximal deep vein thrombosis on bilateral phlebography.

Results - The total incidence of deep yein thrombosis was $16 \%$ in patients receiving unfractionated heparin and $12.6 \%$ in patients receiving low molecular weight heparin $(p=0.45)$, and the incidence of thrombosis of the proximal veins was $13 \cdot 1 \%$ and $2.9 \%$ respectively $(p<0.001)$. Four patients receiving unfractionated heparin and one receiving low molecular weight heparin developed pulmonary embolism. The incidence of bleeding complications was low and comparable in the two groups.

Conclusion-Low molecular weight heparin is at least as effective as unfractionated heparin in preventing deep vein thrombosis and is more effective at preventing thrombosis of the proximal veins in patients undergoing hip replacement. Low molecular weight heparin is not more likely to cause bleeding complications and is simpler to give than unfractionated heparin.

\section{Introduction}

Patients who undergo total hip replacement are at high risk of developing postoperative venous thromboembolic disease.' Without prophylaxis deep vein thrombosis and fatal pulmonary embolism occur in $40-70 \%$ and $1-5 \%$ of patients respectively. ${ }^{24}$ Moreover, it has been repeatedly shown that proximal and bilateral thrombi are much more common after total hip replacement than after general surgery. ${ }^{510}$ This high risk has led to the widespread application of prophylactic measures in hip surgery, but considerable controversy exists about the optimal prophylactic approach. The four main considerations are: firstly, the efficacy of prophylaxis in reducing the incidence of venous thrombosis; secondly, but equally importantly, the bleeding enhancing potential of several prophylactic methods, which threatens the final outcome of the operation; thirdly, the incidence of non-haemorrhagic complications; and, finally, the complexity of giving some prophylactic methods.

Subcutaneous fixed doses of unfractionated heparin reduce by about a half the risk of phlebographically proved deep vein thrombosis after hip replacement without causing a clinically relevant increase in blood loss, " but a considerable risk of deep vein thrombosis of $20-35 \%$ remains. ${ }^{12-15}$ The addition of dihydroergotamine mesylate to unfractionated heparin improves the antithrombotic protection but carries a potential risk of ischaemic disease. ${ }^{16-20}$ Studies in which the doses of subcutaneous heparin were adjusted according to the partial thromboplastin time brought about a significant reduction in the rate of deep vein thrombosis to $10-16 \%$ without an increase in haemorrhagic complications. ${ }^{20-23}$ Frequent adjustment of the heparin dose, however, is very labour intensive..$^{2+}$

Several studies using contrast phlebography for diagnosing deep vein thrombosis showed that subcutaneous low molecular weight heparins or heparinoids were significantly more efficacious in preventing thromboembolic complications than placebo and at least as efficacious or more efficacious than fixed doses of unfractionated heparin. The observed incidences of deep vein thrombosis varied between $10 \%$ and 19\% and major haemorrhagic complications were rarely encountered..$^{25-29}$

Interestingly, low molecular weight heparins seem to have a particularly favourable effect in preventing proximal deep vein thrombosis. The incidences of proximal deep vein thrombosis after hip replacement in studies using low molecular weight heparins and systematic phlebography in all patients were $4 \%$, $7 \cdot 5 \%,{ }^{26} 6.5 \%,{ }^{29}$ and $6.5 \%{ }^{30}$ with enoxaparin; $2 \cdot 4 \%{ }^{2}$ and $0 \%{ }^{28}$ with Fragmin; $3 \cdot 6 \%{ }^{31}$ with Fraxiparine; and $8 \%{ }^{27}$ and $4 \cdot 8 \% \%^{32}$ with Lomoparan.

These favourable results, as well as the simple mode of administration, prompted us to compare treatment with a low molecular weight heparin and treatment by the efficacious but demanding "titrated dose heparin" method. ${ }^{33}$ As lethal pulmonary embolism is thought to be due to migration of proximal thrombi, ${ }^{24}$ the study design took into account primarily the expected incidences of proximal deep vein thrombosis.

\section{Patients and methods}

From September 1988 to May 1989, 1109 patients were admitted for elective total hip replacement to the 
28 participating European departments of orthopaedic surgery. The following eligibility criteria were applied: body weight between $45 \mathrm{~kg}$ and $100 \mathrm{~kg}$, age over 40 years, normal results on Doppler examination of the lower extremities, and having the operation under general anaesthesia.

TABLE I-Reasons for exclusion of patients $(n=700)$ from study before randomisation

\begin{tabular}{lc}
\hline Reason & $\begin{array}{c}\text { No of } \\
\text { patients }\end{array}$ \\
\hline Age $<40$ years & 48 \\
Weight $<45 \mathrm{~kg}$ or $>100 \mathrm{~kg}$ & 38 \\
Abnormal results on preoperative Doppler testing & 40 \\
Written consent not obtained & 211 \\
Recent history of venous thromboembolism ( $<2$ years) & 39 \\
Allergy to contrast media or heparin suspected & 114 \\
Spinal anaesthesia planned & 110 \\
Preoperative haemostasis test result abnormal or history of bleeding & 32 \\
Receiving anticoagulants & 51 \\
Others & 108 \\
\hline Total & $791 \dagger$
\end{tabular}

^Recent history of cerebral stroke ( $<6$ months), hip infection, hip fracture, advanced cancer, or severe renal insufficiency.

tSome patients had more than one exclusion criterion.

In all, 700 patients $(63 \%)$ were excluded before randomisation for reasons specified a priori in the protocol (table I). Hence 409 patients were randomised, by using a balanced assignment for each centre (by the sealed envelope method), to either titrated doses of unfractionated heparin thrice daily or low molecular weight heparin once daily. The study protocol was approved by the ethical committees of all the participating centres.

\section{COMPOUNDS AND ASSAYS}

A single batch of the low molecular weight heparin Fraxiparine (CY 216, Sanofi-Choay Laboratory, Paris) was used. It had an anti-factor specific activity of 27 IIa units (tested against the fourth international heparin standard) and an anti-factor Xa activity of $89 \mathrm{IU} / \mathrm{mg}$ when compared with the international standard for low molecular weight heparins. ${ }^{35}$ It was supplied as a concentrated solution containing 25000 Institute Choay units (ICU)/ml, corresponding to $10400 \mathrm{IU} / \mathrm{ml}$ and supplied in phials containing $0.6 \mathrm{ml} .{ }^{36}$ The unfractionated heparin was a sodium salt of $10000 \mathrm{IU} / \mathrm{ml}$ of heparin (Sanofi-Choay) supplied in ampoules containing $1 \mathrm{ml}$.

Blood was collected four hours after the morning injection into a Diatube H (Diagnostica Stago, Asnières, France) containing $0 \cdot 1$ volume of citric acid $(0 \cdot 11 \mathrm{~mol} /$ 1), theophylline $(15 \mathrm{mmol} / \mathrm{l})$, adenosine $(3.7 \mathrm{mmol} / \mathrm{l})$, and dipyridamole $(0 \cdot 198 \mathrm{mmol} / \mathrm{l})$ mixture. ${ }^{37}$ Activated thromboplastin times were compared with values for each laboratory's control plasma by using the general diagnostics automated activated partial thromboplastin time reagent (Organon Teknika, Fresnes, France). The control plasma was calibrated weekly with general diagnostics plasma verify $\mathrm{H}$ (Organon Teknika). The anti-factor Xa activity of the low molecular weight heparin was assayed by a chromogenic method (Stachrome Heparine, Diagnostica Stago, Asnières, France) and calibrated against a standard (Etalon CY 216, Choay Institute, Paris). All participating centres used the same batch of reagents and followed a methodology described previously ${ }^{38}$ and attached to the study protocol.

\section{PROPHYLACTIC REGIMENS}

Patients receiving unfractionated heparin had subcutaneous injections at intervals of eight hours. The first dose of 4.0 IU was given about 16 hours before surgery. The activated thromboplastin time was measured four hours later so that if necessary the next heparin dose, given two hours before surgery according to a pre-established dose adjustment schedule, could be adjusted. The aim was to keep the patient's activated thromboplastin time at 2-5 seconds above control values. The adjustment was made by standardised stepwise increases or decreases of $500 \mathrm{IU}$ of heparin per injection. The first postoperative injection was given 12 hours after the end of the operation. The activated thromboplastin time for each patient was determined daily: four hours after the morning heparin injection during the first four postoperative days, then every two days up to day 9,10 , or 11 . Dose adjustments were made, if necessary, after each test result.

Patients randomised to receive low molecular weight heparin had one injection of $41 \mathrm{IU} / \mathrm{kg}(100 \mathrm{ICU} / \mathrm{kg})$ of Fraxiparine subcutaneously every day until the third postoperative day. The first injection was given 12 hours before surgery, the second 12 hours after surgery, and the subsequent injections in the mornings of the following days. From day 4 to day 9,10 , or 11 a dose of $62 \mathrm{IU} / \mathrm{kg}$ ( $150 \mathrm{ICU} / \mathrm{kg}$ ) was given. This increase in dosage was incorporated into the study protocol because of earlier observations that higher doses of unfractionated heparin were needed in the later postoperative period to maintain the activated thromboplastin time in the desired range. ${ }^{21}$ For both groups all drugs known to interfere with haemostasis, such as aspirin and other non-steroidal anti-inflammatory drugs, were not allowed during the study, except for indomethacin, which was given up to $75 \mathrm{mg} /$ day by some orthopaedic surgeons in an attempt to prevent ectopic ossifications. All patients wore elastic stockings ("thigh length," Kendall Company, London) from the early postoperative period until day 9,10 , or 11 .

\section{ASSESSMENT OF VENOUS THROMBOEMBOLISM}

Each day patients were clinically examined for signs and symptoms of deep vein thrombosis or pulmonary embolism, or both. If these were present bilateral phlebography, perfusion-ventilation scanning, and, if indicated, pulmonary angiography were performed. In all other patients bilateral phlebography was performed routinely between the ninth and 1lth postoperative day. Phlebograms were evaluated by an independent panel of radiologists, who were unaware of the patient's group assignment. The four reliable signs of deep vein thrombosis described by Rabinov and Paulin were the only criteria accepted for the diagnosis of deep vein thrombosis. ${ }^{3 y}$ All thrombi located in or above the popliteal vein were defined as proximal deep vein thrombosis.

\section{FOLLOW UP}

After stopping the two trial drugs the decision whether or not to continue some form of antithrombotic treatment was left to each investigator. Patients were seen 30 to 50 days after discharge from hospital for possible late occurrence of deep vein thrombosis or pulmonary embolism.

\section{ASSESSMENT OF BLEEDING}

During the study patients were examined daily for evidence of wound haematomas or haematomas at the injection site, or both, as well as other manifestations of bleeding. Bleeding was considered major if there was a wound haematoma necessitating surgical revision, macroscopic haematuria, gastrointestinal bleeding, or any bleeding requiring blood transfusion and interruption of prophylaxis. Transfusion requirements during and after surgery and the volumes of drain fluids collected through the drain were recorded until day 9,10 , or 11 . Haemoglobin concentration and packed cell volume were determined before and after surgery and on the first, fourth, and 10th postoperative days. 


\section{HEPARIN INDUCED THROMBOCYTOPENIA}

To detect heparin induced thrombocytopenia platelet counts were measured before the operation and on the first, fourth, and 10th postoperative days Thrombocytopenia was considered to be present when the platelet count dropped more than $40 \%$ and the absolute count decreased below $100 \times 10^{4} / 1$ on two consecutive measurements. In vitro aggregation tests were performed in these patients.

\section{STATISTICAL ANALYSIS}

The sample size estimation was based on the assumption that about $12 \%$ of patients receiving adjusted doses of unfractionated heparin ${ }^{20-23}$ and $3.5 \%$ of patients receiving Fraxiparine would develop postoperative proximal deep vein thrombosis." Based on these considerations - an $\alpha$ value of 0.05 (two tailed) and a power of $80 \%-177$ patients in each group would be required to detect a difference of this magnitude. Consequently we enrolled 200 patients in each group in anticipation of at least a $10 \%$ drop out rate (because of particularly inadequate, unilateral, or missing phlebograms).

Both an intention to treat analysis and an efficacy analysis - that is, analysis of those patients complying with the protocol-were performed. For the intention to treat analysis only patients with normal bilateral phlebograms were classified as "successes" whereas all patients with an abnormal or inadequate phlebographic outcome, as well as patients in whom a bilateral phlebogram could not be obtained were classified as "failures." For both types of analyses the frequencies of deep vein thrombosis in the two groups were compared by a two tailed Fisher's exact test. The relative risks and their $95 \%$ confidence intervals were estimated according to Kleinbaum et al..$^{41}$ The reductions in risk were calculated according to Fleiss. ${ }^{42}$ Differences in the incidence of major haemorrhage were also calculated with Fisher's exact test. The amount of blood collected by drains, transfusion requirements, haemoglobin concentration, packed cell volume, platelet counts, and anti-factor Xa activity were compared between groups by the two tailed Student's $t$ test. All of the statistical computations were performed by using the SAS software system (SAS Institute, Cary, North Carolina, USA).

\section{Results}

INCIDENCE OF DEEP VEIN THROMBOSIS

In all, 205 patients were randomised to Fraxiparine and 204 to unfractionated heparin. The intention to treat analysis showed no significant differences in the incidence of venous thrombosis between the two groups. Fifty nine (29\%) patients in both groups were classified as failures.

For the efficacy analysis 60 patients $(14 \cdot 6 \%)$ were excluded $(31$ receiving low molecular weight heparin

TABLE II - Reasons for exclusion of patients $(n=60)$ from efficacy analysis. Figures are numbers of patients

\begin{tabular}{lcc}
\hline & $\begin{array}{c}\text { Patients receiving } \\
\text { low molecular } \\
\text { weight heparin }\end{array}$ & $\begin{array}{c}\text { Patients receiving } \\
\text { unfractionated } \\
\text { heparin }\end{array}$ \\
\hline Phlebography not performed or inadequate for interpretation & 9 & 14 \\
Unilateral phlebography & 7 & 4 \\
Phlebography before day 8 or after day 12 & 3 & 6 \\
Treatment stopped or inappropriately given & 5 & 2 \\
Not operated on & 4 & 2 \\
Operated on but prosthesis not implanted & 3 & 1 \\
Exclusion criteria not observed $\dagger$ & 31 & 29 \\
\hline Total & & \\
\hline
\end{tabular}

*Patient died or refused to continue the study or treatment stopped because of major bleeding.

tPreoperative haemostasis test result abnormal or spinal anaesthesia given.
TABLE III-Patients' characteristics and surgical data in two stud groups. Figures are numbers of patients unless otherwise stated

\begin{tabular}{|c|c|c|}
\hline & $\begin{array}{l}\text { Patients receiving } \\
\text { low molecular } \\
\text { weight heparin } \\
\quad(n=174)\end{array}$ & $\begin{array}{l}\text { Patients receiving } \\
\text { unfractionated } \\
\text { heparin } \\
(\mathbf{n}=175)\end{array}$ \\
\hline Mean (SD) age (years) & $64 \cdot 3(14 \cdot 5)$ & $64 \cdot 6(13 \cdot 8)$ \\
\hline $\operatorname{Sex}(\mathbf{M} / \mathbf{F})$ & $73 / 101$ & $85 / 90$ \\
\hline $20 \%$ Overweight & 56 & 51 \\
\hline Varicose veins & 48 & 52 \\
\hline History of thromboembolic event & 12 & 17 \\
\hline Cancer & & 3 \\
\hline Cardiac insufficiency & 9 & 9 \\
\hline \multicolumn{3}{|l|}{ Type of arthroplasty: } \\
\hline Cemented & 119 & 123 \\
\hline Non-cemented & 55 & 52 \\
\hline \multicolumn{3}{|l|}{ Type of implantation: } \\
\hline First & 153 & 153 \\
\hline Revision & 21 & 22 \\
\hline \multicolumn{3}{|l|}{ Surgical approach: } \\
\hline Anterolateral & 56 & 53 \\
\hline Posterolateral & 118 & 121 \\
\hline Not documented & & 1 \\
\hline Mean (range) operating time & $121(45-280)$ & $121(45-390)$ \\
\hline
\end{tabular}

TABLE IV-Frequency and location of deep vein thrombosis in two study groups. ${ }^{\star}$ Figures are numbers (percentages) of patients

\begin{tabular}{lcc}
\hline Anatomical site & $\begin{array}{c}\text { Patients receiving } \\
\text { low molecular } \\
\text { weight heparin } \\
(\mathbf{n}=174)\end{array}$ & $\begin{array}{c}\text { Patients receiving } \\
\text { unfractionated } \\
\text { heparin } \\
(\mathbf{n}=175)\end{array}$ \\
\hline Calf veins alone & $17(9 \cdot 8)$ & $5(2 \cdot 9)$ \\
Calf and proximal veins & $3(1 \cdot 7)$ & $12(6 \cdot 9)$ \\
Proximal veins alone & $2(1 \cdot 1)$ & $11(6 \cdot 3)$ \\
\hline Total & $22(12 \cdot 6)$ & $28(16)$ \\
\hline
\end{tabular}

*Bilateral phlebography was performed in all patients on days 9-11 after surgery.

and 29 receiving unfractionated heparin). Table II lists the reasons for exclusion, which were equally distributed between the two groups. Of the 349 remaining patients, 174 were receiving low molecular weight heparin and 175 unfractionated heparin. The clinical characteristics, risk factors, and surgical data were fully comparable in the two groups (table III).

The analysis (table IV) showed that $22(12 \cdot 6 \%)$ patients receiving low molecular weight heparin and $28(16 \%)$ receiving unfractionated heparin developed deep vein thrombosis (risk reduction $=3.4 \%(95 \%$ confidence interval $-10 \cdot 7 \%$ to $3.9 \%$ ); relative risk $(28 / 175) /(22 / 174)=1 \cdot 27 \quad(0.75$ to $2 \cdot 12) ; p=0 \cdot 45)$. Proximal thrombi were observed in five patients $(2 \cdot 9 \%)$ and 23 patients $(13 \cdot 1 \%)$ respectively (risk reduction $=$ $10 \cdot 2 \%(-15 \cdot 8 \%$ to $-4 \cdot 6 \%)$; relative risk $(23 / 175) /$ $(5 / 174)=4.58(1.78$ to 11.76$) ; \mathrm{p}<0.001)$.

\section{PULMONARY EMBOLISM AND MORTALITY}

One patient receiving low molecular weight heparin and four receiving unfractionated heparin developed symptomatic pulmonary embolism recorded by scintigraphy or angiography, or both, during the initial 10 day study period. Two patients in the unfractionated heparin group died: one had a fatal pulmonary embolism on day 11 , which was confirmed by necropsy, and the other developed hypovolaemic shock due to haemorrhage on the second postoperative day. One patient receiving low molecular weight heparin died of myocardial infarction on the day of the operation.

\section{BLEEDING COMPLICATIONS}

Bleeding complications were assessed in all of the 397 patients who underwent surgery (table V). Major haemorrhagic complications occurred in one patient receiving low molecular weight heparin, who had melaena on the ninth postoperative day, and in three patients receiving unfractionated heparin-macroscopic haematuria developed in one patient, a deep haematoma at the operation site necessitated reintervention in a second patient, and a third patient had a 


\begin{tabular}{|c|c|c|}
\hline & $\begin{array}{l}\text { Patients receiving } \\
\text { low molecular } \\
\text { weight heparin } \\
\quad(n=198)\end{array}$ & $\begin{array}{l}\text { Patients receiving } \\
\text { unfractionated } \\
\text { heparin } \\
(\mathrm{n}=199)\end{array}$ \\
\hline \multicolumn{3}{|l|}{ Bleeding complications: } \\
\hline No with major bleeding & 1 & 3 \\
\hline No with minor wound haematoma & 32 & 27 \\
\hline \multicolumn{3}{|c|}{ Mean (SD) [range] loss of blood through drain $(\mathrm{ml})$ : } \\
\hline Intraoperative period & $739(633)[50-4000]$ & $716(691)[100-5000]$ \\
\hline First to 10th postoperative days & $951(563)[20-3330]$ & $989(734)[20-4505]$ \\
\hline \multicolumn{3}{|c|}{ Mean (SD) [range] transfusion requirement $(\mathrm{ml})$ : } \\
\hline Intraoperative period & $453(549)[0-3250]$ & $472(663)[0-5200]$ \\
\hline First to 10 th postoperative days & $527(633)[0-4700]$ & $440(550)[0-3600]$ \\
\hline \multicolumn{3}{|l|}{ Mean $(\mathrm{SD})$ haemoglobin $(\mathrm{g} / \mathrm{l})$ : } \\
\hline Before surgery & $137(11)$ & $136(10)$ \\
\hline Immediately after surgery & 115 (17) & $115(16)$ \\
\hline Fourth postoperative day & $109(13)$ & $111(11)$ \\
\hline 10th Postoperative day & $111(9)$ & $112(10)$ \\
\hline
\end{tabular}

${ }^{\star}$ For the assessment of bleeding complications all randomised patients were included except the 12 who did not undergo surgery. massive wound haematoma leading to hypovolaemic shock, myocardial infarction, and death.

No significant differences were observed between the two groups with respect to transfusion requirements, the incidence of wound haematomas, loss of blood through the drain, and haemoglobin concentrations before surgery or during the postoperative period. Haematomas at the injection site were significantly more common in those receiving unfractionated heparin than in those receiving low molecular weight heparin $(62 v 26, \mathrm{p}=0.001)$.

\section{THROMBOCYTOPENIA}

Two patients receiving unfractionated heparin (1\%) developed heparin induced thrombocytopenia on the 10 th and 11 th postoperative days. Their platelet counts decreased from $269 \times 10^{9} / 1$ to $70 \times 10^{9} / 1$ and from $450 \times 10^{9} / 1$ to $51 \times 10^{9} / 1$ respectively and in vitro platelet aggregation studies gave positive results. Both patients had proximal thrombi but no clinical evidence of haemorrhage or arterial thrombotic disease. No episodes of thrombocytopenia were observed in those receiving low molecular weight heparin.

\section{HEPARIN DOSAGE AND COAGULATION TESTS}

Patients receiving unfractionated heparin were given a mean (SD) dose of 3679 (1056) IU/injection thrice daily during the 10 days of the study. There was no difference in doses per injection between patients with and without deep vein thrombosis $(3527$ (1240) IU $v 3704$ (1174) IU). The figure depicts the daily mean increases in activated partial thromboplastin time compared with control values for patients

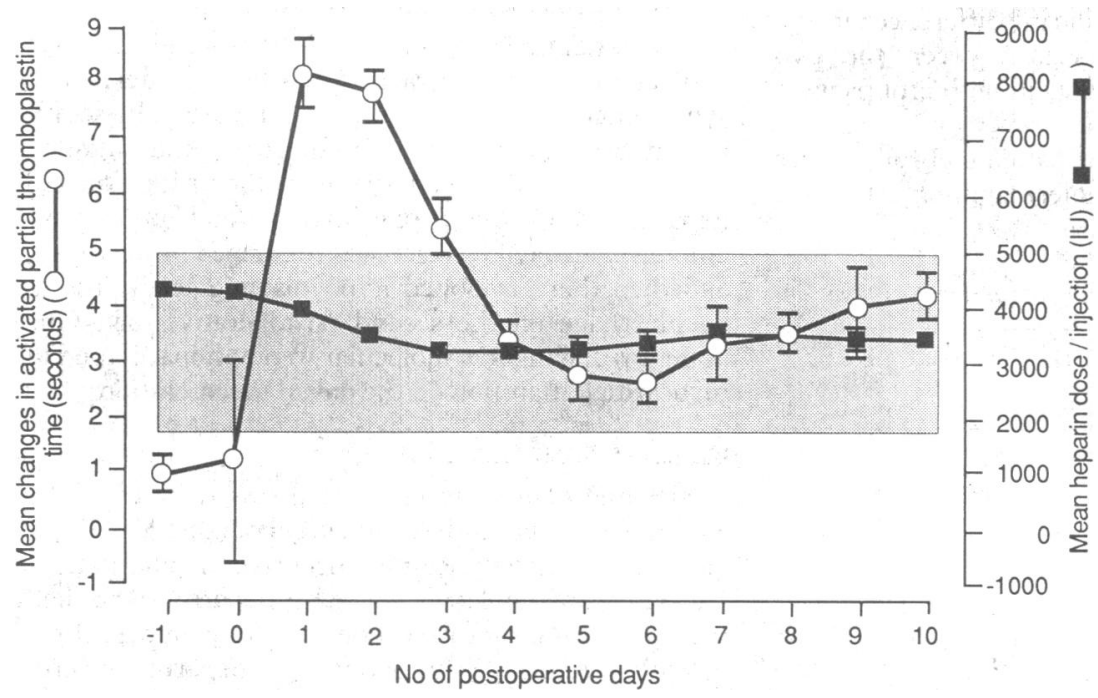

Mean single dosages of heparin given every eight hours in patients receiving unfractionated heparin ( $n=175$ and their mean activated partial thromboplastin times expressed as differences with control values. Bars indicate 1 SEM. Stippled area represents desired range for thromboplastin time receiving unfractionated heparin. Mean activated partial thromboplastin times exceeded the desired range (2-5 seconds above the control values) during the first and second postoperative days. During the subsequent days slight adjustments of the heparin dosage resulted in mean activated partial thromboplastin times within the desired range.

Patients receiving low molecular weight heparin had a mean (SD) dose of Fraxiparine of 3100 (550) IU/day during the first observation period and 4450 (825) IU/day during the second observation period. There was no difference in mean (SD) doses per injection between the patients with and without deep vein thrombosis $(53(14 \cdot 8) \mathrm{IU} / \mathrm{kg} v 55(3 \cdot 8) \mathrm{IU} / \mathrm{kg})$.

Plasma anti-factor Xa activities were measured only in patients receiving low molecular weight heparin. Mean anti-factor Xa activities four hours after injection were between $0.25 \mathrm{IU} / \mathrm{ml}$ and $0.29 \mathrm{IU} / \mathrm{ml}$ during the first three postoperative days and increased to between $0.33 \mathrm{IU} / 1$ and $0.37 \mathrm{IU} / 1$ in the second period (table VI). There seemed to be no accumulation of the drug and mean (SD) anti-factor $\mathrm{Xa}$ activities were not significantly different in the patients with $(n=18)$ and without $(n=139)$ deep vein thrombosis $(0.36$ $(0 \cdot 24) \mathrm{IU} / \mathrm{ml} v 0 \cdot 32(0 \cdot 15) \mathrm{IU} / \mathrm{ml} ; \mathrm{p}=0 \cdot 46)$.

\section{FOLLOW UP}

Of the 394 patients operated on who were alive at the end of the initial 10 day study period, $334(85 \%)$ were available for a follow up examination 30-50 days after discharge from hospital. Antithrombotic prophylaxis was not given in only $12 \cdot 3 \%$ of these patients after phlebography and discontinuation of the two trial drugs. In $87.7 \%$ of patients the investigators maintained for an average of four to six weeks some form of prophylaxis such as continuation of subcutaneous unfractionated heparin or low molecular weight heparin, oral anticoagulation with vitamin $\mathrm{K}$ antagonists, aspirin, or combinations of these. One patient receiving low molecular weight heparin with a history of severe angina pectoris died 24 days after discharge from hospital; necropsy was not performed. Of the patients receiving unfractionated heparin four developed deep vein thrombosis and one had a pulmonary embolism, which was recorded by angiography.

\section{Discussion}

Over the past 20 years many prophylactic measures have been proposed to reduce the high rate of thromboembolic complications after elective total hip arthroplasty. The simplest treatments (aspirin, subcutaneous unfractionated heparin in fixed doses, dextran, and dihydroergotamine heparin) have limited efficacy or produce secondary effects precluding their general use. The more effective methods (vitamin $\mathrm{K}$ antagonists, intermittent pneumatic compression, adjusted doses of unfractionated heparin $)^{202124+344}$ are rarely used because they are difficult to give..$^{45}$

We compared the efficacy and safety of the rather cumbersome method of individually adjusting the eight hourly dose of unfractionated heparin according io the activated partial thromboplastin time ${ }^{21-24}$ with the simpler method of giving one daily weight adjusted dose of low molecular weight heparin. The total incidence of deep vein thrombosis on phlebography was slightly higher $(16 \%)$ in those receiving unfractionated heparin than in those receiving low molecular weight heparin $(12 \cdot 6 \%)$. Although this difference was not significant, it indicates a $27 \%$ greater risk of developing thrombi in the patients receiving unfractionated heparin (relative risk $=1 \cdot 27,95 \%$ confidence interval 0.75 to 2.12 ) (table IV). In an intention to treat analysis all patients with missing, unilateral, or uninterpretable phlebograms were counted as having deep vein throm- 
bosis. In this analysis the incidence of deep vein thrombosis was the same in both groups $(28.8 \% v$ $29 \cdot 0 \%$ ). From these data we conclude that prophylaxis with low molecular weight heparin is no worse than that with the best previously available method - that is, individual adjustment of the unfractionated subcutaneous heparin dosage according to the partial thromboplastin times four hours after the morning injection.

The most noteworthy aspect of our study is the very low incidence of proximal deep vein thrombosis in patients receiving low molecular weight heparin compared with those receiving unfractionated heparin $(2.9 \%$ v $13.1 \%, \mathrm{p}<0.001)$. Patients receiving the adjusted heparin doses thus had a four to five times greater risk of proximal thrombi than those receiving low molecular weight heparin (relative risk $=4.58,1.78$ to $11 \cdot 76$ ). Patients with proximal deep vein thrombosis have at least a $35 \%$ chance of developing pulmonary embolism, as evidenced by perfusion-ventilation scanning. ${ }^{46}$ Thus the fourfold reduction in incidence of proximal deep vein thrombosis in our patients receiving low molecular weight heparin may be related to the low risk of clinically apparent pulmonary embolism in this group. Indeed, four patients receiving unfractionated heparin experienced clinically apparent pulmonary embolism compared with only one patient receiving low molecular weight heparin (this difference was not significant, but the number of events was small). All of these patients had deep vein thrombosis of the iliofemoral veins.

The incidence of major bleeding complications and all other measurements of blood loss were comparable between the two groups. Many orthopaedic surgeons are concerned that the prophylactic administration of small doses of subcutaneous heparin might result in a higher incidence of serious wound haematomas or of postoperative bleeding or in an increase of the blood transfusion requirement. Yet studies where prophylaxis with low molecular weight heparin was compared with placebo showed no differences in any of these variables. ${ }^{25} 2728$

In one recent study, which used fairly large doses of enoxaparin twice daily (corresponding to a daily dose of $6000 \mathrm{IU}$ of low molecular weight heparin twice a day) a significant increase in the plasma anti-factor $\mathrm{Xa}$ activity six hours after the morning injection was observed from day 1 to day $14 .{ }^{25}$ No such accumulation could be detected in our study with mean doses of $3100 \mathrm{IU}$ of Fraxiparine a day during the first three days and 4450 IU from day 4 to day 10 (table VI). In addition to the higher dosages used by Turpie $e t \mathrm{al}^{25}$ the longer half life for anti-factor Xa activity of enoxaparin after subcutaneous injection (360 minutes) compared with that of Fraxiparine (214 minutes) ${ }^{48}$ may account for the observed accumulation of anti-factor $\mathrm{Xa}$ activity.

Some methodological aspects of the study warrant comment. The dosage of unfractionated heparin was regularly adjusted according to the patients' activated thromboplastin time and therefore it was not practicable to conduct the study as a double blind trial. To exclude interpretation bias all phlebograms were read by three independent radiologists who had no knowledge

TABLE VI-Mean anti-factor $X a$ activity in patients receiving low molecular weight heparin

\begin{tabular}{lcccc}
\hline & \multicolumn{5}{c}{ No of postoperative days } \\
\cline { 2 - 5 } & 1 & 3 & 4 & 10 \\
\hline $\begin{array}{l}\text { No of samples tested } \\
\begin{array}{l}\text { Mean }(\text { SEM }) \text { anti-Xa } \\
\text { activity }(\text { IU } / \mathrm{ml})\end{array}\end{array}$ & 149 & 108 & 148 & 132 \\
\hline «amples were collected four hours after the morning injection of Fraxi- \\
parine.
\end{tabular}

of the treatment given. Also, an independent group of physicians, who were unaware of the treatment allocation, reviewed and classified all of the histories of patients with outcomes other than deep vein thrombosis (that is, major bleeding, pulmonary embolism, and death) and those who dropped out. Care was taken to standardise laboratory procedures. Each centre used the same batch of activated thromboplastin time reagent and of a commercial control plasma. Finally, a representative range of patients was admitted to the trial in 28 European orthopaedic services comprising smaller hospitals as well as large university departments. We believe, therefore, that our results are valid and relevant to all patients undergoing elective hip surgery under general anaesthesia.

Our results compare favourably with our previous studies with unfractionated heparin adjusted to the activated thromboplastin time ${ }^{21}$ and with recent prospective randomised studies in which other low molecular weight heparin preparations were given for preventing deep vein thrombosis after elective hip surgery and mandatory bilateral phlebography was used for diagnosing deep vein thrombosis. ${ }^{23} 25.32$ The total incidence of deep vein thrombosis in all of these studies varied from $4 \cdot 9 \%$ to $19 \cdot 4 \% .{ }^{212325.32}$ The incidence of proximal deep vein thrombosis of $2.9 \%$ in the patients receiving low molecular weight heparin compares favourably with the results obtained in other trials using low molecular weight heparin or heparinoids, which vary from $2 \cdot 4 \%$ to $8 \%$. $^{235532}$

Few studies provide follow up data on patients who benefited from antithrombotic prophylaxis. A second (smaller) peak in the incidence of deep vein thrombosis has been observed after stopping low doses of unfractionated or low molecular weight heparin. ${ }^{49}$ The clinical diagnosis of deep vein thrombosis is notoriously unreliable. Nevertheless, we were surprised that none of the patients who had received the low molecular weight heparin experienced clinical signs of deep vein thrombosis or pulmonary embolism but that there were five such events during the follow up period in the patients who received unfractionated heparin.

We conclude that the low molecular weight heparin Fraxiparine, with the dose adjusted for body weight and given subcutaneously once a day, is at least as efficacious and safe in the prevention of total deep vein thrombosis after elective hip replacement as individually adjusted unfractionated heparin given thrice daily. In addition, the low molecular weight heparin was significantly more efficacious in preventing deep vein thrombosis of proximal veins and is simpler to use than unfractionated heparin.

We thank the following people and their centres for enrolling patients into this trial: Dr François Widmer (CHUV, Lausanne); Dr Laure Besson (CHU J Courmont, Lyons); Dr Philippe Tisserand (CHU La Timone, Marseille); Dr Annick Baud (CHU Trousseau, Tours); Dr Daniel Samson (Hôpital de la Conception, Marseille); Dr Patrick Simon (CHU de Hautepierre, Strasbourg); Professor Gilles Bousquet (CHRU de Bellevue, Saint-Etienne); Professor Karel Hamelynck (Slotervaartziekenhuis, Amsterdam); Professor Hendrik Claessens (RUG, Gand); Dr Anne de Tinteniac (CHU Morvan, Brest); Professor Jean Pierre Delagoutte (CHU Brabois, Nancy); Professor Jean Puget (CHU Rangueil, Toulouse); Dr Xavier Lapeyrere (Hôpital A Mignot, Versailles); Dr Paul Antoine Tulasne (Centre de Traumatologie, Illkirch); Dr Frank Handelberg (UZ, VUB, Brussels); Dr Georges de Brouckère (Clinique Caty, Baudour); Dr Sylvain Terver (Hôpital St Jacques, Clermont-Ferrand); Dr Daniel Mazza (Clinique du Plateau, Clamart); Professor René Claude Touzard (Hôtel-Dieu, Paris); Professor Alain Le Rebeller and Dr Dominique Dumora (CHU Pellegrin, Bordeaux); Dr Christiane Pech (CHU Purpan, Toulouse); Dr Pierre Delacroix (Clinique du Parc, Lyons); Dr Dominique Grouille (CHU Dupuytren, Limoges); Dr Michel Delecroix (CHU Hôpital B, Lille); Dr Toon Borms (St Jozefkliniek, Bornem); 
Professor Edoardo Ascari (Institute di Clinica Medico, Pavia); Dr Jean Pierre Lamas (CHU Cochin, Paris). We also thank Drs Pascal d'Azemar and Xavier Frapaise for participating in the study protocol design; the radiologists Drs Herve Muntlak and Jean Marc Pernès and Professor Jean Michel Tubiana for reading the phlebograms; $\mathrm{Mr}$ Michel Kindermans for the statistical evaluation; and Professor Jan Wouter ten Cate for critical reading of the manuscript.

1 Merli GJ, Martinez J. Prophylaxis for deep vein thrombosis and pulmonary embolism in the surgical patient. Med Clin North Am 1987;71:377-97.

2 Salzman EW, Hirsh J. Prevention of venous thromboembolism. In: Colman RW, Hirsh J, Marder VJ, Salzman EW, eds. Hemostasis and thrombosis. Basic principles and clinical practice. 2nd ed. Philadelphia: J B Lippincot, 1987:1252-65.

3 Hampson WG, Harris FC, Lucas HK, Roberts PH, McCall IW, Jackson PC, et al. Failure of low-dose heparin to prevent deep-vein thrombosis after hipreplacement arthroplasty. Lancet 1974;ii: 795-7.

4 Sikorski JM, Hampson WG, Staddon GE. The natural history and aetiology of deep vein thrombosis after total hip replacement. $\mathcal{f}$ Bone foint Surg $[\mathrm{Br}]$ 1981;63:171-7.

5 Stamatakis JD, Kakkar VV, Sagar S, Lawrence D, Nairn D, Bentley PG. Femoral vein thrombosis and total hip replacement. BMF 1977;ii:223-5.

6 Bergqvist D, Elvelin R, Eriksson U, Hjelmstedt A. Thrombosis following hip arthroplasty. A study using phlebography and $125 \mathrm{I}$-fibrinogen test. Acta Orthop Scand 1976;47:549-57.

7 Evarts CM, Feil EJ. Prevention of thromboembolic disease after elective surgery of the hip. F Bone Foint Surg [Am] 1971;53:1271-80.

8 Nillius AS, Nylander $G$. Deep vein thrombosis after total hip replacement: a clinical and phlebographic study. $B r f$ Surg 1979;66:324-6.

9 Salzman EW, Harris WH. Prevention of venous thrombocmbolism in orthopedic patients. F Bone foint Surg /Am] 1976;58:903-13.

10 Morris GK, Henry AP, Preston BJ. Prevention of deep-vein thrombosis by low-dose heparin in patients undergoing total hip replacement. Lancet 1974;ii:797-800.

11 Collins R, Scrimgeour A, Yusuf S, Peto R. Reduction in fatal pulmonary embolism and venous thrombosis by perioperative administration of subcutaneous heparin. Overview of results of randomized trials in general, orthopedic and urologic surgery. $N$ Engl f Med 1988;318:1162-73.

12 Venous Thrombosis Clinical Study Group. Small doses of subcutaneous sodium heparin in the prevention of deep vein thrombosis after elective hip operations. Br f Surg 1975;62:348-50.

13 Gallus AS, Hirsh J, Tuttle RJ, Trebilcock R, O'Brien SE, Carroll JJ, et al. Small subcutaneous doses of heparin in prevention of venous thrombosis. N Engl F Med 1973;288:545-51.

14 Sagar S, Nairn D, Stamatakis JD, Maffei FH, Higgins AF, Thomas DP, et al. Efficacy of low-dose heparin in prevention of extensive deep-vein thrombosis in patients undergoing total-hip replacement. Lancet 1976;i:1151-4.

15 Moskovitz PA, Ellenberg SS, Feffer HL, Kenmore PI, Neviaser RJ, Rubin $\mathrm{BR}$, et al. Low-dose heparin for prevention of venous thromboembolism in $\mathrm{BR}$, et al. Low-dose heparin for prevention of venous thromboembolism in
total hip arthroplasty and surgical reparr of hip fractures. $\mathcal{F}$ Bone foint Surg total hip arthroplasty and

16 Kakkar VV, Stamatakis JD, Bentlev PG, Lawrencè D, de Haas HA, Ward VP. Prophylaxis for postoperative deep-vein thrombosis. Synergistic effect of heparin and dihydroergotamine. FAMA 1979;241:39-42.

17 Beisaw NE, Comerota AJ, Groth HE, Merli GJ, Weitz HH, Zimmerman RC, et al. Dihydroergotamine/heparin in the prevention of deep-vein thrombosis after total hip replacement. $\mathcal{F}$ Bone foint Surg [Am] 1988;70:2-10.

18 Van den Berg E, Rumpf KD, Fröhlich H, Walterbusch G, Müller-Vahl H, Reilmann $\mathrm{H}$, et al. Vascular spasm during thromboembolism prophylaxis with heparin-dihydroergotamine. Lancet 1982;ii:268-9.

19 Gent M, Roberts RS. A meta-analysis of the studies of dihydroergotamine plus heparin in the prophylaxis of deep vein thrombosis. Chest 1986;89(suppl): 3965-4005

20 Leyvraz. PF, Bachmann F, Vuilleumier B, Berthet S, Bohnet J, Haller E. Adjusted subcutaneous heparin versus heparin plus dihydroergotamine in prevention of deep-vein thrombosis after total hip arthroplasty. 7 Arthroplasty 1988;3:81-6.

21 Leyvraz PF, Richard J, Bachmann F, Van Melle G, Treyvaud JM, Livio JJ, et al. Adjusted versus fixed dose subcutaneous heparin in the prevention of deep-vein thrombosis after total hip replacement. $N$ Engl F Med 1983;309: 954-8.

22 Hurley PB, Graor RA, Wilde AH, Borden LS, Stulberg BS. An evaluation of six different deep vein thrombosis prophylactic techniques for total hip and
knee replacement: a preliminary report [abstract]. Trans Orthop Res Soc knee replace $1986 ; 11: 303$.

23 Dechavanne M, Ville D, Berruyer M, Trepo F, Dalery F, Clermont N, et al. Randomised trial of a low-molecular-weight heparin (Kabi 2165) versus adjusted-dose subcutaneous standard heparin in the prophylaxis of deepvein thrombosis after elective hip surgery. Haemostasis 1989;1:5-12.
24 Harris WH, Athanasoulis CA, Waltman AC, Salzman EW. Prophylaxis of deep-vein thrombosis after total hip replacement. Dextran and externa pneumatic compression compared with 1.2 or 0.3 gram of aspirin daily. f Bone foint Surg [A $\mathrm{Am}]$ 1985;67:57-62.

25 Turpie AG, Levine MN, Hirsh J, Carter CJ, Jay RM, Powers PJ, et al. A randomized controlled trial of a low-molecular-weight heparin (enoxaparin) to prevent deep-vein thrombosis in patients undergoing elective hip surgery. N Engl F Med 1986;315:925-9.

26 Planès A, Vochelle $\mathrm{N}$, Mazas $\mathrm{F}$, Mansat $\mathrm{CH}$, Zucman J, Landais A, et al. Prevention of postoperative venous thrombosis: a randomized trial comparing unfractionated heparin with low molecular weight heparin in patients undergoing total hip replacement. Thromb Haemost 1988;60:407-10.

27 Hoek J, Nurmohamed MT, ten Cate H, ten Cate JW, Büller HR. Prevention of deep vein thrombosis (DVT) following total hip replacement by a low molecular weight heparinoid (Org 10172) [abstract]. Thromb Haemost 1989;62:1637

28 Törholm C, Broeng L, Jörgensen PS, Bjerregaard P, Josephsen L, Jörgensen $\mathrm{PK}$, et al. Thromboprophylaxis by low-molecular-weight heparin in elective hip surgery. A placebo controlled study. I Bone foint Surg [Br] 1991;73 $434-8$

29 Levine MN, Hirsh J, Gent M, Turpie AG, Leclerc J, Powers PJ, et al. Prevention of deep-vein thrombosis after elective hip surgery. A randomized trial comparing low-molecular-weight heparin with standard unfractionated heparin. Ann Intern Med 1991;114:545-51.

30 Planes A, Vochelle N, Fagola M, Feret J, Belland M. Prevention of deep-vein thrombosis after total hip replacement. The effect of low-molecular weight heparin with spinal and general anaesthesia. $f$ Bone foint Surg $[\mathrm{Br}]$ 1991;73:418-22.

31 Simon P, Kindermans A, Kempf JF, Postel M. Efficacité et tolérance d'une héparine de bas poids moleculaire dans la prevention des thromboses veineuses profondes lors des arthroplasties totales de hanche réglées. Essai prospectif, multicentrique. J Chir (Paris) 1990;127:252-7.

32 Estoppey D, Hochreiter J, Breyer HG, Jakubek H, Leyvraz PF, Haas S, et al. Org 10172 (Lomoparan) versus heparin-DHE in prevention of thrombo-
(L) Org 10172 (Lomoparan) versus heparin-DHE in prevention of thrombo-
embolism in total hip replacement. A multicentre trial [abstract]. Thromb Haemost 1989;62:1107.

33 Salzman EW. Low-molecular-weight heparin. Is small beautiful? Engl f Med 1986;315:957-9.

34 De la Caffinière JY, Mignot $M$, Bruch JM. Le caillot dangereux en chirurgie orthopédique. Résultats d'une enquête par phlébographie pré- et postopératoire des membres inférieurs. Rev Chir Orthop 1981;67:47-58.

35 Barrowcliffe TW, Curtis AD, Johnson EA, Thomas DL. An international standard for low-molecular-weight heparin. Thromb Haemost 1988;60:1-7.

36 Lormeau JC, Hajiar R. Méthode de titrage de l'activité anti-facteur Xa du CY 216. Pathol Biol 1988;36:335-7.

37 Constant G, Gouault-Heilmann M, Martinoli JL. Heparin inactivation during blood storage. Its prevention by blood collection in citric acid, theophylline, adenosine, dipyridamole-CTAD mixture. Thromb Res 1983;31:365-74.

38 Aiach $M$, Sie P. Surveillance biologique des traitements par les héparines de bas poids moléculaire. Ann Biol Clin 1988:46:715-8.

39 Rabinov K, Paulin S. Roentgen diagnosis of venous thrombosis in the leg. Arch Surg 1972;104:134-44.

40 Kelton PJ, Sheridan D, Brain H, Powers PJ, Turpie AG, Carter CJ. Clinical usefulness of testing for a heparin-dependent platelet aggregating factor in patients with suspected heparin-associated thrombocytopenia. $f$ Lab Clin Med 1984;103:606-12.

41 Kleinbaum DG, Kupper LL, Morgenstern H. Epidemiologic research: principles and quantitative methods. Belmont California: Wadsworth, 1982.

42 Fleiss JL. Statistical methods for rates and proportions. New York: John Wiley and Sons, 1981.

43 Roberts HR, Adel S, Webster D, Bernstein EF, Buring J, Demling RH, et al. Prevention of venous thrombosis and pulmonary embolism. NIH Consensus Conference. FAMA 1986;256:744-9.

44 Hyers ThM, Hull RD, Weg JG. Antithrombotic therapy for venous thromboembolic disease. Chest 1989;95(suppl):37-51

45 Paiement GD, Wessinger SJ, Harris WH. Survey of prophylaxis against venous thromboembolism in adults undergoing hip surgery. Clin Orthop 1987;223:188-93

46 Dorfman GS, Cronan JJ, Tupper TB, Messersmith RN, Denny DF, Lee CH Occult pulmonary embolism: a common occurrence in deep venous thrombosis. Am F Radiol 1987; 148:263-6.

47 Hull RD, Hirsh J, Carter CJ, Jay RM, Dodd PE, Ockelford PA, et al. Pulmonary angiography, ventilation lung scanning and venography for clinically suspected pulmonary embolism with abnormal perfusion lung scan. Ann Intern Med 1983;98:891-9.

48 Verstraete $M$. Pharmacotherapeutic aspects of unfractionated and lowmolecular-weight heparins. Drugs 1990;40:498-530.

49 Bergqvist D. Postoperative thromboembolism. Frequency, etiology, prophylaxis. Berlin: Springer, 1983:32-3.

(Accepted 19 July 1991)

\section{ONE HUNDRED YEARS AGO}

There has been much, and not unnaturally hostile, criticism on the refusal of the Government of India to interfere in a case of this barbarous practice in India on the ground that it was a case of voluntary suffering. It consists in suspending the volunteer devotee by means of two hooks inserted into the muscles of the back, which is supposed to propitiate the goddess of evil practices. The same practice was very common, and is to this day practised, among the American and Canadian Indians as part of the education of the brave, and of the ceremonies of the annual dances and solemn festivities. It has long been practised in the Indian "Reservations," where the degenerate remnants of the red man find the last home of

his dwindling race. Till lately it was a frequent custom to make parties of pleasure to witness these ceremonies. Quite lately the missionaries and local superintendents have been persuading most of their Protégés to give up the practice, but not, we believe, with uniform success. In India the devotee is usually narcotised with "bhang" (Indian hemp), and suffers but little pain but much damage. Among the American tribes this is not the case, and the extent of the pain and the fortitude with which it is endured is the measure of the brave's courage and manhood, and one of his titles to future honour and respect.

(British Medical fournal 1891;ii:1109) 